\title{
Reproductive biology of the orange mud crab Scylla olivacea (Herbst, 1796) from the Pichavaram mangroves of south-east India
}

\author{
C. VISWANATHAN, M. PRAVINKUMAR, T. V. SURESH, V. ELUMALAI AND S. M. RAFFI \\ Centre of Advanced Study in Marine Biology, Faculty of Marine Sciences, Annamalai University \\ Parangipettai - 608 502, Tamil Nadu, India \\ e-mail:drcvishwanathan@gmail.com
}

\begin{abstract}
The present study was conducted to assess the size distribution, sex ratio, size at first sexual maturity, fecundity and spawning season of the commercially important orange mud crab Scylla olivacea (Herbst, 1796) in Pichavaram mangroves in south-east India. This study is the first contribution to the knowledge of reproductive biology of S. olivacea from the Indian coast. Size distribution analysis in the fishery revealed the irrational exploitation of undersized $S$. olivacea. The estimated sex ratio deviated from equality, being 1:0.87, revealing a male domination. Size at first sexual maturity was determined to be $87 \mathrm{~mm}$ in carapace width $(\mathrm{CW})$ in females. Fecundity ranged from 1.16 to 3.53 million in females of 76 to $135 \mathrm{~mm} \mathrm{CW}$. Breeding takes place year-round with a peak in pre-monsoon, indicating that it is a prolific breeder. Results revealed that immature individuals of $S$. olivacea contributed significantly to the catches and thus an effective management of the resource by framing minimum legal size is crucial so that the females are allowed to spawn at least once prior to capture.
\end{abstract}

Keywords: Fecundity, Pichavaram, Reproductive biology, Sex ratio, Scylla olivacea

\section{Introduction}

Mud crabs of the genus Scylla are large portunids that inhabit estuaries and coastal waters and are typically associated with mangroves in tropical and subtropical areas of the Pacific and Indian Oceans. Mud crabs command high price in domestic and export seafood markets and also provide livelihood security to many traditional and small scale fishers in south-east Asian countries (Angell, 1992). Over the last three decades, exploitation of mud crab populations has intensified tremendously in many countries. Owing to fishing pressure, loss of habitat, unsustainable practise of fishing of gravid females as well as undersized crabs and indiscriminate collection of wild seeds to grow-out practices, the natural stocks are declining alarmingly in many regions (Angell, 1992; Le Vay et al., 2007; Mirera, 2011; Viswanathan et al., 2016).

Information pertaining to the reproductive biology of commercially overexploited species is fundamental for understanding its population dynamics, which is essential for effective fishery management modules. Despite the importance of mud crab fisheries in the Indo-West Pacific, literature on its biology is limited which has hindered the successful management of the fishery (Ikhwanuddin et al., 2011).
Traditionally, mud crabs were considered to belong to a single species, Scylla serrata, before the genus Scylla was revised to include four species (S. serrata, S. tranquebarica, S. olivacea and S. paramamosain) (Keenan et al., 1998). Since then, ecological and biological studies have focussed on particular species with most of them on $S$. serrata as a single species of the genus and a few on other species. In the present study, an investigation was conducted on one of the commercially overexploited orange mud crab, S. olivacea (Herbst, 1796) from Pichavaram, south-east India, where this species is predominant in the catches over the other species. The key morphological characters of $S$. olivacea includes red to brown coloured carapace, low rounded frontal spines, single reduced spine in the carpus of the chelipeds and absence of obvious polygonal markings in the legs and abdomen (Keenan et al., 1998). Investigations on reproductive biology of $S$. olivacea are limited and have been done on the populations in Thailand (Tongdee et al., 2001; Overton and Macintosh, 2002; Koolkalya et al., 2006; Hamasaki et al., 2011), Malaysia (Ikhwanuddin et al., 2011; Waiho et al., 2016) and Japan (Ogawa et al., 2011; Ogawa et al., 2012). However, such works from Indian waters are not available. Therefore, this study was conducted to determine the key reproductive biological parameters, such as size distribution, sex ratio, size at first sexual maturity, fecundity and spawning 
season, which are required for formulating effective resource management models.

\section{Materials and methods}

Mud crab sampling

Pichavaram mangrove $\left(11^{\circ} 29^{\prime} \mathrm{N}, 79^{\circ} 46^{\prime} \mathrm{E}\right)$, located on the east coast of India (Fig. 1), is one among the largest mangrove ecosystems in India. Specimens of S. olivacea (Fig. 2) were collected between June 2010 and May 2012, from gillnet catches and baited traps operated by local fishermen at Pichavaram. The sampled live crabs were identified, sexed, carapace widths (CW) measured to an accuracy of $0.5 \mathrm{~mm}$ using a vernier caliper and body weight $(\mathrm{BW})$ and ovary weight $(\mathrm{OW})$ measured to an accuracy of $0.01 \mathrm{~g}$ using a digital weighing balance.

\section{Sex ratio}

Sex ratio was tested for equality in different months using Chi-square test using the formula:

$$
\chi^{2}=\sum \frac{(\mathrm{O}-\mathrm{E})^{2}}{\mathrm{E}}
$$

where, $O$ is the observed value and $E$ is the expected value.

\section{Size at first sexual maturity}

The abdominal flaps of all the crabs were screened to examine the maturity stage. Female crabs which have undergone pubertal moult with wide darkened abdominal flaps, were considered as mature. Female crabs were dissected for determining the stages of gonadal maturation
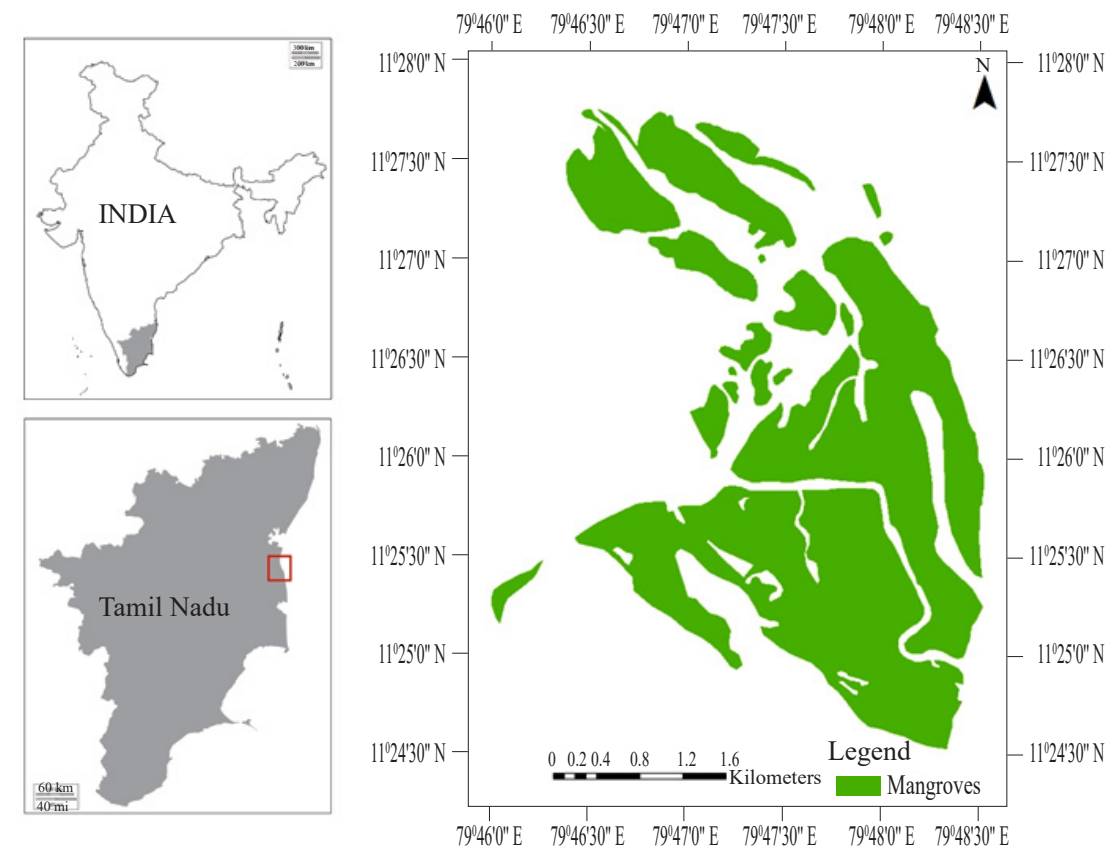

Fig. 1. The study area: Pichavaram mangroves, South-east India

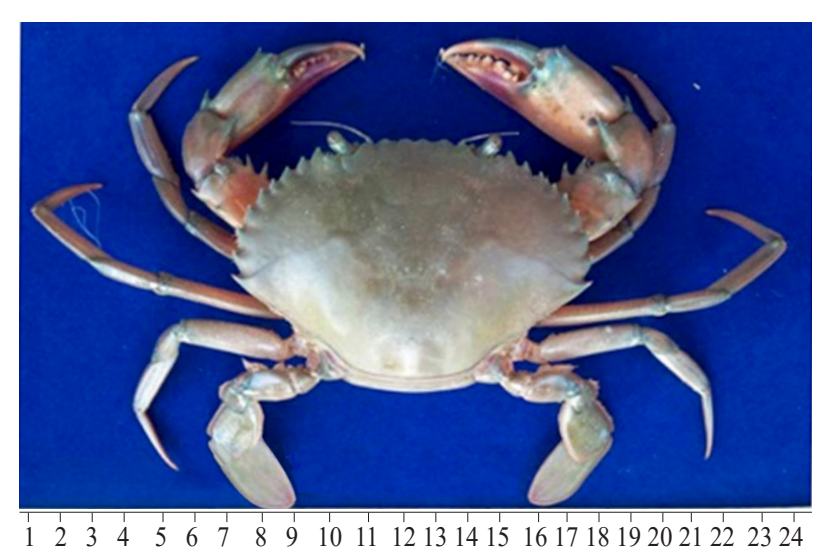

Fig. 2. Mud crab S. olivacea collected from Pichavaram mangroves by examining the morphological appearances (Quintio et al., 2007). Based on the developmental conditions of ovaries, crabs were grouped into five maturity stages: I - immature, II - early maturing, III - late maturing, IV - gravid/ripe and V - spent according to their colour and size. The percentages of maturity stages were estimated under different size classes. These percentages were converted to a probit scale and plotted against size classes. A regression plot was drawn using the data points. The size at first sexual maturity was determined by the size at which at least $50 \%$ of crabs attained sexual maturity $\left(S M_{50}\right)$ with respect to the maturation stage as per probit analysis (Robertson and Kruger, 1994). 


\section{Fecundity}

Pre-spawning fecundity was estimated by counting the number of ova present in the mature ovary (Jayamanna and Jinadasa, 1993). Ovaries in stages III and IV were carefully removed and fixed in Gilson fluid. To calculate fecundity, the mature ovaries were wiped in a blotting paper to remove moisture and then pieces of $0.5 \mathrm{~g}$ each were dissected out from the anterior, middle and posterior regions of the ovary and each piece into five sub-samples to an accuracy of $0.01 \mathrm{~g}$ using an electronic weighing balance. Later, each sub-sample was squeezed in $100 \mathrm{ml}$ distilled water and again sub-samples (triplicates), each of $1 \mathrm{ml}$, were taken using a pipette and the number of ova in each subsample was counted under a binocular microscope. The obtained values of fecundity $(F)$ were correlated with variables such as $\mathrm{CW}, \mathrm{BW}$ and $\mathrm{OW}$.

\section{Spawning season}

Seasonal changes in gonado-somatic index (GSI) as well as percentage of mature females were taken into consideration for the prediction of spawning season in $S$. olivacea at Pichavaram. Every month, adult crabs were randomly collected based on their dark widened abdominal flap. For GSI estimation, female gonads were dissected, weighed and calculated using the following equation:

$$
\text { GSI }=\frac{\text { Weight of ovary }(\mathrm{g})}{\text { Weight of the animal }(\mathrm{g})} \times 100
$$

Further, ovigerous females and spent crabs (predictable by the swollen spermathecae) were recorded.

\section{Results}

\section{Size distribution}

Size distribution was constructed for 6094 individuals of S. olivacea by plotting frequency of occurrence against different size classes. The size ranges $(\mathrm{CW})$ of males and females of S. olivacea were found to be $45-148 \mathrm{~mm}$ and 45-140 mm respectively (Fig. 3). The first recruitment of S. olivacea into the commercial catches in Pichavaram mangrove starts around $45 \mathrm{~mm} \mathrm{CW}$ for both sexes. The maximum size of $S$. olivacea caught in the catches were 147.5 and $139.4 \mathrm{~mm}$ for male and female respectively. The mean CW did not vary significantly between sexes $(104.33 \pm 77.44 \mathrm{~mm}$ for males, $104.38 \pm 80.16 \mathrm{~mm}$ for females). In males, the major mode was observed to be $85-92 \mathrm{~mm}$ in $\mathrm{CW}$, whereas in females it was found to be $101-108 \mathrm{~mm}$. The dominant size groups in the catches were in the range of $77-124 \mathrm{~mm}(62 \%)$ and $85-124 \mathrm{~mm}$ $(55 \%)$ in males and females respectively. In general, the predominance of small size groups $(45-68 \mathrm{~mm})$ was in post-monsoon and sub-adults and adults $(69-116 \mathrm{~mm})$ were dominant in summer and pre-monsoon.

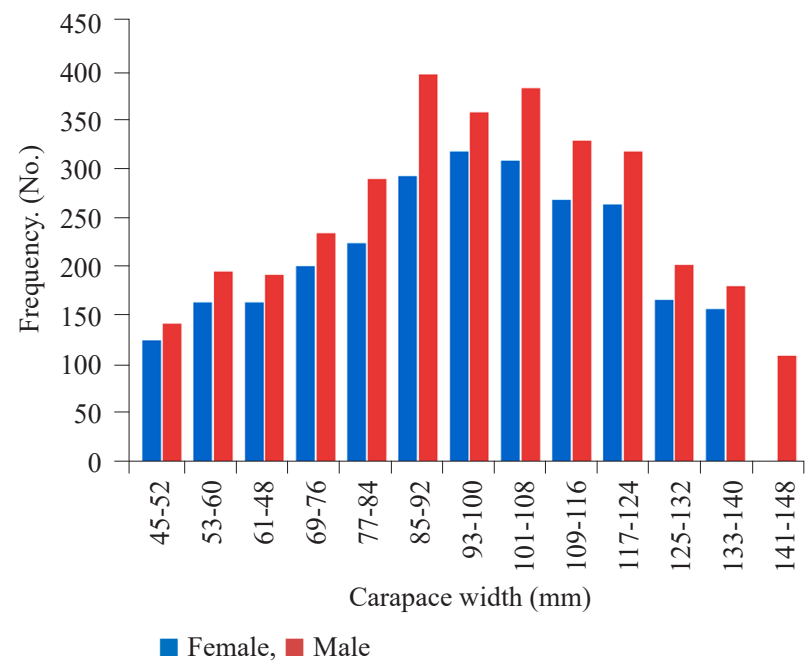

Fig. 3. Size distribution of $S$. olivacea . (each size class $=8 \mathrm{~mm}$ )

\section{Sex ratio}

Overall, 6094 crabs were sexed and the male: female ratio estimated was 1:0.87 (Table 1). The results indicated a significant deviation from the expected 1:1 ratio $\left(\chi^{2}=29.22 \mathrm{p}<0.005\right)$ which evinced the existence of a heterogeneous distribution between sexes in the population of $S$. olivacea. Significant differences in the sex ratio was observed between October and December with a male bias (1:0.59-0.63). Generally, male biased sex ratio was observed in all the months except February (1:1.29) during the study period.

\section{Size at first sexual maturity}

A total of 667 female crabs of $\mathrm{CW}$ ranging between 45 and $140 \mathrm{~mm}$ were dissected and their gonadal maturation stages were recorded. The percentage of mature female crabs, based on different gonadal maturation stages are given in Table 2. The smallest mature crabs were traced in the $\mathrm{CW}$ range of $69-76 \mathrm{~mm}(74 \mathrm{~mm})$ while the largest immature crabs were observed in 109-116 mm $(112 \mathrm{~mm})$. The first three size classes were immature crabs (45-52; 63-60 and 61-68 mm). The middle size classes, ranging between 69 and $116 \mathrm{~mm}$ had both immature and mature crabs. The last three size classes $(117-124 ; 125-132$ and 133-140) had only mature crabs. The relationship between the proportion of mature-immature crabs in each size class based on gonadal stages confirmed the logistic function and indicate that $50 \%$ female crabs mature at $87 \mathrm{~mm}$ (Fig. 4).

Crabs with immature ovaries were significantly dominant in post-monsoon season. In summer, predominantly crabs with gonadal stages II and III were observed. Crabs with mature ovaries were traced in all the months with predominance in pre-monsoon. High 
Table 1 . Monthly variation in sex ratio of S. olivacea

\begin{tabular}{|c|c|c|c|c|c|c|}
\hline \multirow{2}{*}{ Season } & \multirow{2}{*}{ Month } & \multicolumn{2}{|c|}{$\%$} & \multirow{2}{*}{$\begin{array}{l}\text { Sex ratio } \\
\text { (M: F) }\end{array}$} & \multirow{2}{*}{$\chi^{2}$ value } & \multirow{2}{*}{$\mathrm{p}$ value } \\
\hline & & Male & Female & & & \\
\hline \multirow[t]{3}{*}{ Pre-monsoon } & Jul & 53 & 47 & $1: 0.9$ & 1.889 & $>0.05$ \\
\hline & Aug & 51 & 49 & $1: 0.96$ & 0.288 & $>0.05$ \\
\hline & Sep & 51 & 49 & $1: 0.97$ & 0.148 & $>0.05$ \\
\hline \multirow[t]{3}{*}{ Monsoon } & Oct & 62 & 38 & $1: 0.61$ & 21.321 & $<0.005$ \\
\hline & Nov & 62 & 38 & $1: 0.63$ & 15.426 & $<0.005$ \\
\hline & Dec & 63 & 37 & $1: 0.59$ & 18.198 & $<0.005$ \\
\hline \multirow[t]{3}{*}{ Post-monsoon } & Jan & 50 & 49 & $1: 0.99$ & 2.068 & $>0.05$ \\
\hline & Feb & 44 & 56 & $1: 1.29$ & 7.659 & $<0.01$ \\
\hline & Mar & 55 & 45 & $1: 0.81$ & 6.206 & $<0.05$ \\
\hline \multirow[t]{4}{*}{ Summer } & Apr & 54 & 46 & $1: 0.84$ & 4.009 & $<0.05$ \\
\hline & May & 55 & 45 & 1.0 .81 & 5.916 & $<0.05$ \\
\hline & Jun & 53 & 47 & $1: 0.88$ & 2.109 & $>0.05$ \\
\hline & Total & 53 & 47 & $1: 0.87$ & 29.22 & $<0.005$ \\
\hline
\end{tabular}

Table 2. Distribution of mature female crabs of $S$. olivacea in different size groups

\begin{tabular}{ll}
\hline Size group $(\mathrm{mm})$ & Percentage of mature female \\
\hline $45-52$ & 0 \\
$53-60$ & 0 \\
$61-68$ & 0 \\
$69-76$ & 17.9 \\
$77-84$ & 33.3 \\
$85-92$ & 52.2 \\
$93-100$ & 69.2 \\
$101-108$ & 81.1 \\
$109-116$ & 93 \\
$117-124$ & 100 \\
$125-132$ & 100 \\
$133-140$ & 100
\end{tabular}

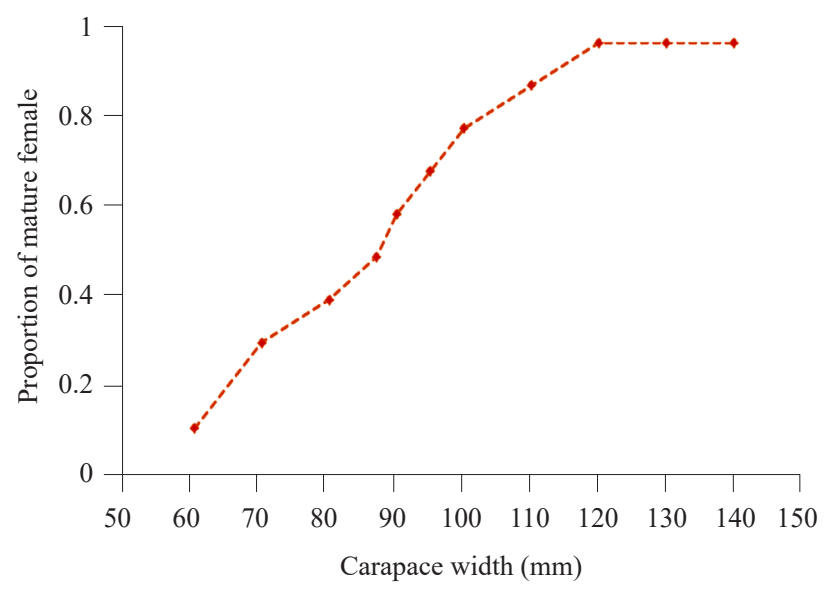

Fig. 4. Size at maturity $\left(\mathrm{CW}_{50}\right)$ of female $S$. olivacea

percentages of spent ovaries were observed in the late monsoon. The results revealed that immature female crabs contributed $33 \%$ in the landings.
Fecundity

A total of 248 crabs, $\mathrm{CW}$ ranging from 76 to $135 \mathrm{~mm}$ were used to estimate pre-spawning fecundity. The minimum fecundity in S. olivacea was 1166575 , observed in a crab having $76 \mathrm{~mm} \mathrm{CW}$, while the maximum fecundity was 3539724 recorded in a crab having $135 \mathrm{~mm} \mathrm{CW}$. The average fecundity was $2310415 \pm 766378$ for $S$. olivacea with the mean CW of $106.2 \pm 17.9$. The relationship between fecundity and CW, BW and OW is illustrated in Fig. 5. The four variables were significantly correlated. The significant correlation between the variables was reflected in the scatter plot by trend exhibit power function: Fecundity $=367.36 \mathrm{CW}^{1.8679}$ $\left(\mathrm{R}^{2}=0.8229\right), 114013 \mathrm{BW}^{0.5567}\left(\mathrm{R}^{2}=0.7836\right)$ and 217640 $\mathrm{OW}^{0.7998}\left(\mathrm{R}^{2}=0.7977\right)$.

Spawning season

A total of 894 female gonads were removed, weighed and analysed to assess the GSI. The estimated GSI in females ranged between $2.16 \pm 0.38$ and $12.39 \pm 1.15$ (Fig. 5). The GSI values varied between months, with peaks in July to September (pre-monsoon), afterwards declined upto January and then increased. Mature females were observed throughout the months with peaks in July to September (Fig. 6). The decrease in the GSI after September indicated that crabs were moving for spawning to other areas, presumably to offshore. The seasonal changes in GSI, as well as, percentage of mature females were correlated. A few berried females were found in the months of August to October during the study period. Mature spent crabs with swollen spermathecae and translucent ovaries were generally observed in monsoon.

\section{Discussion}

The present study, conducted on the reproductive biology of S. olivacea in Pichavaram mangroves, south-east 


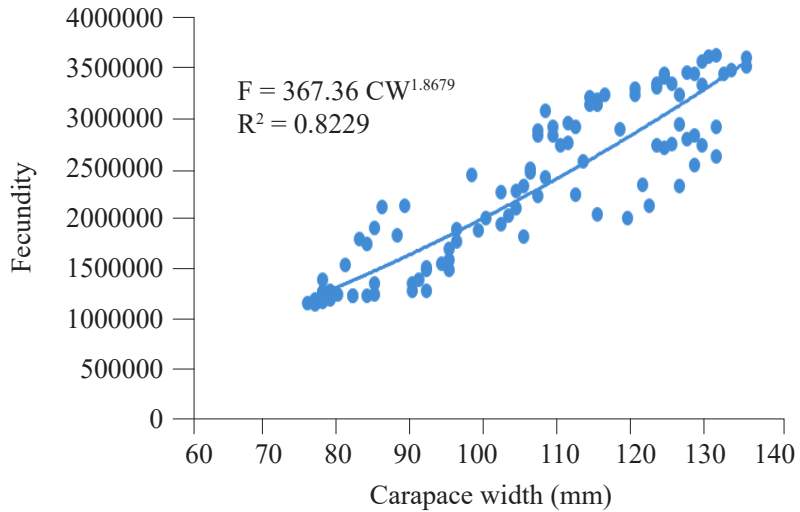

(a)

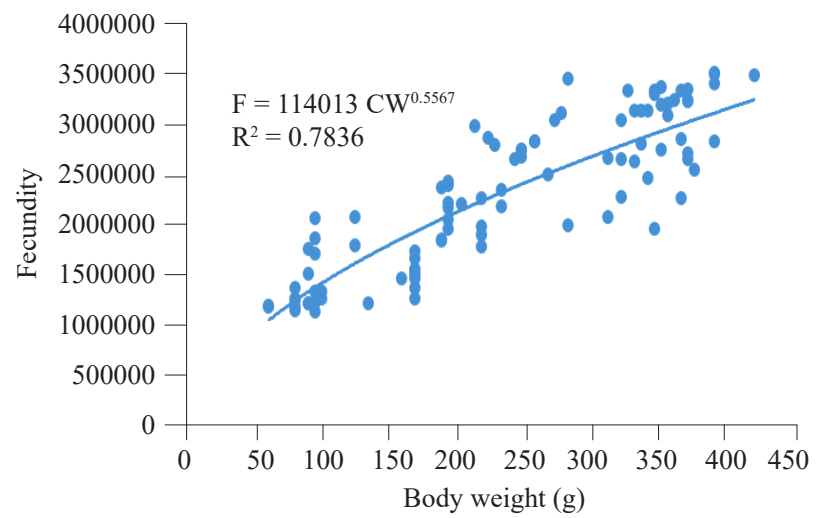

(b)

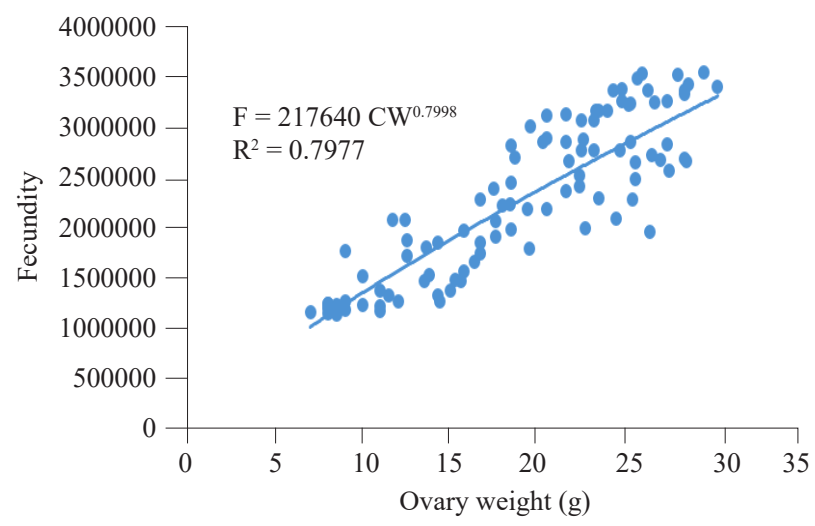

(c)

Fig. 5. Relationship between fecundity and (a) carapace width; (b) body weight and (c) ovary weight of S. olivacea

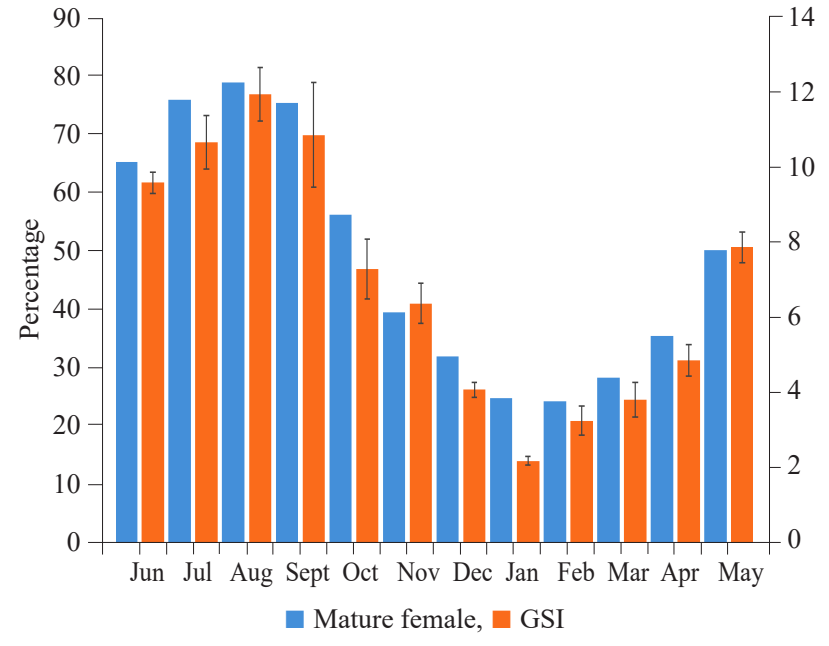

Fig. 6. Temporal variation in the percentage of mature female and GSI (Mean $\pm \mathrm{SD}$ ) of $S$. olivacea

India, is the first from the country. Size distribution analysis of a commercially overexploited species is vital for better understanding of its population contributing to the fishery as well as to know whether the size groups represented in the catches are juveniles or adults, which provides information for developing an effective management module. The results of the size distribution revealed that in $S$. olivacea the stock recruitment in the fishery starts around the size of $45 \mathrm{~mm} \mathrm{CW}$. This was relatively comparable with the smallest crabs of S. olivacea recorded in the fishery in Ranong, Thailand (50 mm), Buswang, Philippines (35 mm) and Sarawak, Malaysia (53 mm) (Moser et al., 2005; Walton et al., 2006; Ikhwanuddin et al., 2011). The largest crab caught during this study was $147 \mathrm{~mm}$ and this was larger than reported in Thailand $(135 \mathrm{~mm})$ and smaller than reported in Malaysia (153 mm) (Moser et al., 2005; Walton et al., 2006; Ikhwanuddin et al., 2011). The size range observed in the Urado Bay, Japan was between 70 and $140 \mathrm{~mm}$ (Ogawa et al., 2012) and this again was comparable with the maximum size observed in the present study. In Thailand, Hamasaki et al. (2011) observed size ranges between 86 and $129 \mathrm{~mm}$. Size distribution of commercial crab catches is influenced by gear selectivity (Walton et al., 2006) as well as fishing intensity.

Results of size distribution studies show that immature female crabs contribute $33 \%$ in the landings indicating the unsustainable overfishing in Pichavaram owing to 
non-selective gear used in fishery. Overexploitation of mud crabs in different localities of Indian coast was reported by various researchers (Kathirvel, 1980; Shanmugam and Bensam, 1981; Srinivasagam and Raman, 1985; Sarada, 1997). Overexploitation of mud crab resources along the south-east Asian countries has intensified tremendously over the last three decades (Angell, 1992; Moser et al., 2005; Walton et al., 2006; Le Vay et al., 2007; Mirera, 2011). Lack of awareness on sustainability has led to the indiscriminate collection of juveniles and overfishing of mud crabs in this region. Educating the fisher folk on the need for conservation of mud crab resources could be done through awareness programs, emphasising community stewardship and individual responsibility for mud crab conservation. Further, stock enhancement of mud crabs through sea ranching can be appropriately done by concerned resource managers under close monitoring.

The present study found that the size at first sexual maturity of female $S$. olivacea was $87 \mathrm{~mm}$. Tongdee (2001) reported that $S$. olivacea started to attain maturity at $70 \mathrm{~mm} \mathrm{CW}$ and at $100 \mathrm{~mm} \mathrm{CW}$ all were found to be mature. The median size of mature female crabs was $86 \mathrm{~mm} \mathrm{CW}$ which is close to the results of our study. Overton and Macintosh (2002) stated that the $S M_{50}$ was found to be $91.2 \mathrm{~mm}$ for $S$. olivacea in Bandon Bay, Thailand, which is also comparable to the present study. Koolkalya et al. (2006) found the size at first maturity as 94 $\mathrm{mm}$ in S. olivacea from Andaman Sea, Thailand. The sizes of pre-pubertal and mature females of $S$. olivacea from the Gulf of Thailand were reported to be in the range of 82-88 $\mathrm{mm}$ and 101-123 $\mathrm{mm} \mathrm{CW}$, respectively (Hamasaki et al., 2011). Ikhwanuddin et al. (2011) and Waiho et al. (2016) observed that female $S$. olivacea reached $S M_{50}$ at $86 \mathrm{~mm}$, which is also in line with the results of the present study. The differences in size at first sexual maturity are influenced by geographical locations (Hines, 1989; Ikhwanuddin et al., 2011). Some studies have reported that size at first sexual maturity for Scylla spp. were higher at higher latitudes when compared to lower latitudes (Quinn and Kojis, 1987; Angell, 1992).

In the present study, statistical deviation from expected 1:1 has clearly indicated the male-biased sex ratio. Studies of sex ratio in immature and mature crabs in Scylla spp. revealed male dominance in Ranong Province, Thailand (Tongdee, 2001). Koolkalya et al. (2006) reported male-biased sex ratio in S. olivacea from Andaman Sea, Thailand. These findings are similar to our results. The low occurrence of female crabs during the monsoon season underlines the fact that females migrate to offshore for spawning as reported by various authors from different localities (Hyland et al., 1984; Hill, 1994, Moser and Macintosh, 2001; Moser et al., 2005). The male-biased sex ratio during monsoon season has also been reported from Malaysia and Japan (Ikhwanuddin et al., 2011; Ogawa et al., 2011).

The pre-spawning fecundity of $S$. olivacea observed in Andaman Sea ranged between 12,29,472 to 47,87,967 eggs with an average of 25,85,098 eggs (Koolkalya et al., 2006), which is close to the average fecundity observed in our study. The average fecundity of female $S$. olivacea in China waters was two million eggs (Jia and Chen, 2001), which too is close to our results. In earthen ponds, S. olivacea can produce 0.4 to 2.7 million zoea weighing 360 to $465 \mathrm{~g}$ (Quinitio et al., 2002).

The GSI reported from the Andaman Sea (1.9 \pm 3.3 to $8.2 \pm 5.8)$ was comparable to the present study (Koolkalya et al., 2006). Tongdee (2001) observed that the GSI ranged between 1.8 and 6.5 in S. olivacea from Ranong Province, Thailand. The comparison of percentage mature females and GSI indicate breeding throughout the year with a peak in pre-monsoon (Fig. 6). During our study period, a few ovigerous crabs were also observed in this season. The mature females decreased after September, after GSI peaks, indicating that crabs were moving for spawning to different areas. This was supported by significant deviation in the proportion of mature females in October to December (Table 1) as well as predominance of spent crabs. So this immediate fall in percentage of mature females after the pre-monsoon season might be owing to the migration of ovigerous females into the offshore regions for spawning. Larval studies on Scylla spp. (Swarupa, 1986) revealed that the breeding season was an extended one with higher intensity during the pre-monsoon season in east coast of India.

The present study revealed that breeding peaks in August (pre-monsoon) and subsequently larval development and succession of juveniles take place within 3 to 4 months of duration leading to the high occurrence of small sized crabs in late monsoon and post-monsoon. Chandrasekaran and Natarajan (1994) estimated higher occurrence of juvenile crabs of Scylla spp. in the beginning of post-monsoon in Pichavaram mangroves and this was relatively comparable to our results. The time spent for offshore spawning by females and their pelagic larvae equates to 1-2 months as females are ovigerous for 13 days (Anil and Suseelan, 1999).

In Scylla spp., the spawning has been reported throughout the year from India (Pillay and Nair, 1973; Prasad and Neelakantan, 1989; Mohapatra et al., 2011) as well as from other countries (Arriola, 1940; Quinn and Kojis, 1987; Koolkalya et al., 2006). In tropical estuaries, the period of peak spawning generally coincides with the periods of high nutrient input associated with monsoon 
or cyclonic rainfall (Heasman, 1980). In Pichavaram mangroves, the prominent litter fall triggers the nutrient load; coupled with the exchange of neritic waters from the adjacent Bay of Bengal; brackishwater from the adjoining Vellar and Coleroon estuaries; freshwater from an irrigation channel (Khan Shakib canal) as well as from the main channel of the Coleroon River; provide sufficient nutrient load that maintains primary and secondary production, which triggers continued reproduction round the year in mud crabs. Moreover, reproduction in tropical populations will be more protracted and less seasonal (Heasman, 1980).

Lack of awareness leading to the indiscriminate collection of juveniles and overfishing resulting in gradual decline in landings as well as commercially exploited size of $S$. olivacea in Pichavaram mangroves is an alarming situation. Our observations warrant an immediate focus on the effective conservation management of mud crab resources. Mud crabs in this region can be sustained by adopting management measures such as: regulating the minimum legal size limited to $95 \mathrm{~mm} \mathrm{CW}$ for $S$. olivacea so that it can breed at least once in its life span; banning collection of berried females; fishing ban during the pre-monsoon season to safeguard recruitment to the stock and to augment the future stock of the rapidly depleting commercially important Scylla spp.; stock enhancement of mud crabs through sea ranching with hatchery produced seeds by concerned fishery managers and by conducting awareness programmes for fisher folk for community stewardship and individual responsibility in mud crab conservation

\section{Acknowledgements}

Acknowledgements are due to Ministry of Environment and Forest, Government of India for the funding support (Grant No. 22-9/2008-CS-I). We sincerely acknowledge the critical evaluation and valuable suggestions of Dr. Soundarrajan, that helped to improve clarity of the manuscript.

\section{References}

Angell, C. A. 1992. The mud crab. Report of the seminar on the mud crab culture and trade held at Swat Thani, Thailand, November 5-8, 1991. In: Angell, C. A. (Ed.), Seminar on mud crab culture and trade, Bay of Bengal programme, BOBP Report, Chennai, 239 pp.

Anil, M. K. and Suseelan, C. 1999. Laboratory rearing and seed production of the mud crab Scylla oceanica (Dana). J. Mar. Biol. Ass. India, 41: 38-45.

Arriola, F. J. 1940. A preliminary study of the life history of Scylla serrata (Forskal). The Philippines J. Sci., 73: 437-456.
Chandrasekaran, V. S. and Natarajan, R. 1994. Seasonal abundance and distribution of seeds of mud crab Scylla serrata in the Pichavaram mangrove, South-east India. J. Aqua. Trop., 9: 343-350.

Hamasaki, K., Matsui, N. and Nogami, M. 2011. Size at sexual maturity and body size composition of mud crab Scylla spp. caught in Don Sak, Bandon Bay, Gulf of Thailand. Fish. Sci., 77: 49-57. DOI: 10.1007/s12562-010-0307-6.

Heasman, M. P. 1980. Aspects of the general biology and fishery of the mud crab Scylla serrata (Forskal) in Moreton Bay, Queensland. Ph. D., Thesis, University of Queensland, $506 \mathrm{pp}$.

Hill, B. J. 1994. Offshore spawning by the portunid crab Scylla serrata (Crustacea: Decapoda). Mar. Biol., 120: 379-384. DOI: $10.1007 / \mathrm{BF} 00680211$

Hines, A. H. 1989. Geographic variation in size at maturity in brachyuran crabs. Bull. Mar. Sci., 45: 356-368.

Hyland, S. J., Hill, B. J. and Lee, C. P. 1984. Movement within and between different habitats by the portunid crab Scylla serrata. Mar. Biol., 80: 57-61. DOI: 10.1007/BF00393128.

Ikhwanuddin, M., Azmie, G., Juriah, H. M., Zakaria, M. Z. and Amabak, M. A. 2011. Biological information and population features of mud crab, genus Scylla from mangrove areas of Sarawak, Malaysia. Fish. Sci., 108: 299-306. DOI: 10.1016/j.fishres.2011.01.001.

Jayamanna, S. C. and Jinadasa, J. 1993. Size at maturity and spawning periodicity of the mud crab Scylla serrata (Forskal) in the Negombo Estuary. J. Nat. Sci. Coun. Sri Lanka, 21: 141-152. doi.org/10.4038/jnsfsr.v21i1.8095.

Jia, J. and Chen, J. 2001. Sea farming and sea ranching in China. FAO Fishery Technical Paper 418: 71 pp.

Kathirvel, M. 1980. Abundance of portunid crab seeds in Cochin backwater. Abstract No. 94, Proceedings of the Symposium on Coastal Aquaculture, 12-18 January 1980. Marine Biological Association of India, Kochi, Kerala, India, p. 55.

Keenan, C. P., Davie, P. J. F. and Mann, D. L. 1998. A revision of the genus Scylla De Haan, 1833 (Crustacea: Decapoda: Brachyura: Portunidae). The Raffles Bull. Zool., 46: 217-245.

Koolkalya, S., Thapanand, T., Tunkijjanujij, S., Havanont, V. and Jutagate, T. 2006. Aspects in spawning biology and migration of the mud crab Scylla olivacea in the Andaman Sea, Thailand. Fish. Manag. Ecol., 13: 391-397. DOI: $10.1111 / j .1365-2400.2006 .00518 . x$.

Le Vay, L., Ut, V. N. and Walton, M. 2007. Population ecology of the mud crab Scylla paramamosain (Estampador) in an estuarine mangrove system; a mark-recapture study. Mar. Biol., 151: 1127-1135. DOI: 10.1007/s00227-006-0553-4.

Mirera, O. D. 2011. Trends in exploitation, development and management of artisanal mud crab (Scylla serrata Forsskal,1775) fishery and small-scale culture in Kenya: 
An overview. Ocean Coast. Manag., 54: 844-855. DOI: 10.1016/j.ocecoaman.2011.08.001.

Mohapatra, A., Mohanty, S. K. and Mohanty, R. K. 2011. Juvenile abundance and post-larval incursion of mud crabs (Scylla spp.) in Chilika lagoon. Indian J. Geo-Mar. Sci., 40: 834-840.

Moser, S. M. and Macintosh, D. J. 2001. Diurnal and lunar patterns of larval recruitment of Brachyura into a mangrove estuary system in Ranong Province, Thailand. Mar. Biol., 138: 827-841. DOI: $10.1007 / \mathrm{s} 002270000502$.

Moser, S., Macintosh, D., Laoprasert, S. and Tongdee, N. 2005. Population ecology of the mud crab Scylla olivacea: a study in the Ranong mangrove ecosystem, Thailand, with emphasis on juvenile recruitment and mortality. Fish. Res., 71: 27-41. DOI: 10.1016/j.fishres.2004.07.008.

Ogawa, C. Y., Hamasaki, K., Dan, S. and Kitada, S. 2011. Fishery biology of mud crabs Scylla spp. at Iriomote Island, Japan: species composition, catch, growth and size at sexual maturity. Fish. Sci., 77: 915-927. DOI: 10.1007/ s12562-011-0408-x.

Ogawa, C. Y., Hamasaki, K., Dan, S., Obata, Y. and Kitada, S. 2012. Species composition, reproduction and body size of mud crabs, Scylla spp., caught in Urado Bay, Japan. J. Crust. Biol., 32(5): 762-768. doi.org/10.1163/ 193724012 X649787.

Overton, J. L. and Macintosh, D. J. 2002. Estimated size at sexual maturity for female mud crabs (genus Scylla) from two sympatric species within Ban Don Bay, Thailand. J. Crust. Biol., 22: 790-797.

Pillay, K. K. and Nair, N. B. 1973. Observations on the breeding biology of some crabs from the south-west coast of India. J. Mar. Biol. Ass. India, 15: 754-770.

Prasad, P. N. and Neelakantan, B. 1989. Maturity and breeding of the mud crab, Scylla serrata (Forskal) (Decapoda: Brachyura: Portunidae). Proc. Indian Acad. Sci. Ani. Sci., 98: 341-349.

Quinitio, E. T., Parado-Estepa, F. D. and Rodriguez, E. 2002. Seed production of mud crab Scylla spp. Aqua. Asia, 8: 29-31.

Quinitio, E. T., Pedro, J. D. and Parado-Estepa, F. D. 2007. Ovarian maturation stages of the mud crab Scylla serrta.
Aqua. Res., 38: 1434-1441. doi.org/10.1111/j.1365-2109. 2007.01650.x.

Quinn, N. J. and Kojis, B. L. 1987. Reproductive biology of Scylla spp. (Crustacea: Portunidae) from the Labu Estuary in Papua New Guinea. Bull. Mar. Sci., 41: 234-241.

Robertson, W. D. and Kruger, A. 1994. Size at maturity, mating and spawning in Portunid crab Scylla serrata (Forskal) in Natal, South Africa. Est. Coast. Shelf Sci., 39: 185-200.

Sarada, P. T. 1997. Exploitation of mud crab Scylla serrata (Forskal) from Korapuzha Estuary, Kerala. J. Mar. Biol. Ass. India, 39:113-117.

Shanmugam, S. and Bensam, P. 1981. On the fishery for the crab Scylla serrata (Forskal) at Tuticorin during 1974-75. Indian J. Fish., 27: 102-110.

Srinivasagam, S. and Raman, K. 1985. Crab fisheries of Pulicat Lake with special reference to catches from the southern sector. Proceedings of the Symposium on Harvest and Post-Harvest Technology of Fish, 24-27 November 1982. Society of Fisheries Technologists (India), Kochi, p. 63-68.

Swarupa, K. M. C. 1986. Studies on the inshore planktonic decapoda off Baptala coast. Ph. D. Thesis, Nagarjuna University, India, $313 \mathrm{pp}$.

Tongdee, N. 2001. Size distribution, sex ratio and size at maturity of mud crab (Scylla spp.) in Ranong Province, Thailand. Asian Fish. Sci., 14: 113-120.

Viswanathan, C., Pravinkumar, M., Suresh T. V., Elumalai, V. and Raffi, S. M. 2016. Carapace width-weight relationship, age, growth and longevity of the mud crab Scylla olivacea (Herbst, 1796) in the Pichavaram mangroves, south-east India. J. Mar. Biol. Ass. UK., 96(7): 1379-1386. DOI: $10.1017 / \mathrm{S} 0025315415001216$.

Waiho, K., Fazhan, H. and Ikhwanuddin, M. 2016. Size distribution, length-weight relationship and size at the onset of sexual maturity of the orange mud crab, Scylla olivacea, in Malaysian waters. Mar. Biol. Res., 12(7): 726-738. doi.org/10.1080/17451000.2016.1200726.

Walton, M. E., Le Vay, L., Lebata, J. H., Binas, J. and Primavera, J. H. 2006. Seasonal abundance, distribution and recruitment of mud crabs (Scylla spp.) in replanted mangroves. Est. Coast. Shelf Sci., 66: 493-500. DOI: $10.1016 /$ j.ecss.2005.09.015. 